Article

\title{
Insecticidal Activity of Bacteria from Larvae Breeding Site with Natural Larvae Mortality: Screening of Separated Supernatant and Pellet Fractions
}

\author{
Handi Dahmana ${ }^{1,2}\left(\mathbb{D}\right.$, Didier Raoult ${ }^{1,2}$, Florence Fenollar ${ }^{2,3}$ and Oleg Mediannikov ${ }^{1,2, *(D)}$ \\ 1 IRD, AP-HM, MEPHI, Aix Marseille University, 13005 Marseille, France; \\ handi.dahmana@etu.univ-amu.fr (H.D.); didier.raoult@gmail.com (D.R.) \\ 2 IHU-Méditerranée Infection, 13005 Marseille, France; florence.fenollar@univ-amu.fr \\ 3 IRD, AP-HM, SSA, VITROME, Aix Marseille University, 13005 Marseille, France \\ * Correspondence: olegusss1@gmail.com; Tel.: +33-(0)4-13-73-24-01; Fax: +33-(0)4-13-73-24-02
}

Received: 15 May 2020; Accepted: 17 June 2020; Published: 18 June 2020

check for updates

\begin{abstract}
Mosquitoes can transmit to humans devastating and deadly pathogens. As many chemical insecticides are banned due to environmental side effects or are of reduced efficacy due to resistance, biological control, including the use of bacterial strains with insecticidal activity, is of increasing interest and importance. The urgent actual need relies on the discovery of new compounds, preferably of a biological nature. Here, we explored the phenomenon of natural larvae mortality in larval breeding sites to identify potential novel compounds that may be used in biological control. From there, we isolated 14 bacterial strains of the phylum Firmicutes, most of the order Bacillales. Cultures were carried out under controlled conditions and were separated on supernatant and pellet fractions. The two fractions and a 1:1 mixture of the two fractions were tested on L3 and early L4 Aedes albopictus. Two concentrations were tested ( 2 and $6 \mathrm{mg} / \mathrm{L}$ ). Larvae mortality was recorded at 24,48 and $72 \mathrm{~h}$ and compared to that induced by the commercialized B. thuringiensis subsp. israelensis. Of the 14 strains isolated, 11 were active against the $A$. albopictus larvae: 10 of the supernatant fractions and one pellet fraction, and mortality increased with the concentration. For the insecticide activity prediction in three strains of the Bacillus cereus complex, PCR screening of the crystal (Cry) and cytolytic (Cyt) protein families characteristic to $B$. thuringiensis subsp. israelensis was performed. Most of the genes coding for these proteins' synthesis were not detected. We identified bacterial strains that exhibit higher insecticidal activity compared with a commercial product. Further studies are needed for the characterization of active compounds.
\end{abstract}

Keywords: mosquito-borne disease; bacteria; biological control; insecticidal activity; bacteria secondary metabolites; Bacillus

\section{Introduction}

Diseases transmitted by arthropods participate in a major part to infectious diseases' morbidity and mortality worldwide, and mosquitoes are number one in terms of public health importance, transmitting such deadly diseases as malaria (Anopheles), filariasis (Culex) and dengue (Aedes) that cause millions of deaths every year [1]. To control them, a large number of chemical compounds have been used. However, their intensive use resulted in numerous drawbacks such as the contamination of water and food sources, poisoning of non-target fauna and flora, concentration in the food chain and resistance [2]. The use of biological control and biopesticides based on natural products appears to be the best alternative.

The interest in the effectiveness of microorganisms and their metabolites for insect control dates back decades. Approximately 1500 naturally occurring microorganisms have been identified as 
potentially insecticidal agents [1] and metabolites from 942 microbial isolates were screened for insecticidal properties [3]. Bacillus spp. are ubiquitous bacteria found in a wide range of terrestrial and aquatic environments and are known for their wide range of physiological abilities allowing them to grow in every environment and to compete desirably with other organisms, especially through their ability to form extremely resistant spores and to produce metabolites [4]. Prior to the discovery of Bacillus thuringiensis subsp. israelensis (Bti) and Lysinibacillus sphaericus, bacteria had not received much attention as a source of promising molecules for the control of insects of medical and veterinary importance. Nonetheless, Bti and L. sphaericus products now dominate the commercial market for the control of mosquito larvae [5].

Among the different classes of proteins produced by B. thuringiensis, three classes of larvicidal proteins are well-known: Cry (crystal proteins), Cyt (cytolytic toxicity) and Vip (proteins throughout the vegetative phase), some of which are toxic against a wide range of insect orders, nematodes and human cancer cells. It was demonstrated that $C y t$ toxins possess less toxicity against mosquito larvae than Cry toxins. Numerous factors may increase the risk of acquiring resistance in target insects and also have a negative impact on non-target insects [6-9]. Several proteins are toxic for dipteran insects such as Cry2, Cry4, Cry10, Cry11, Cry16, Cry17, Cry19 and Cyt, and several general and specific sets of primers we designed in order to screen Bacillus spp. isolates for their presence [10].

The selection of resistance to $B t i$ in mosquitoes has been achieved under laboratory conditions [11] but despite having been used for several decades, there is little evidence for the selection of $B t i$ resistance under field conditions [9]. In contrast, various levels of laboratory and field resistance are widely found in L. sphaericus products, depending on prior exposure to naturally existing strains, population genetic background and gene exchange with untreated populations, as well as product application strategies [12].

Several studies have been carried out by isolating large collections of Bacillus strains to explore their biological activities, including antibacterial, insecticide and others [1,3,13-16]. Most of these beneficial compounds are largely used in several medical or economic purposes, especially to control various diseases in animals, humans and plants, when applied as a biological control agent [13]. Different studies investigated the bacterial populations of breeding sites and their possible effects on mosquito larval populations [17]. New Bacillus isolates were reported harboring new $\delta$-endotoxin genes and/or different forms of the known endotoxin genes and considered very promising in the search of novel endotoxins [16]

In the present study, we proceeded as follows:

i. We explored 20 larval breeding sites that have never been treated with insecticides, looking for possible mosquito larval mortality. Only one had a natural larva mortality;

ii. We isolated bacterial strains from this larva breeding site that presented a natural mortality of mosquito larvae;

iii. We tested the bacteria-free supernatant and disrupted bacterial pellet separately, or the mixture of both of the different strains of bacteria.

We suspected that bacterial insecticide may explain this phenomenon and attempted to explore it.

\section{Results}

\subsection{Isolated Strains}

A total of 173 strains from 9 different genera were isolated. Since Bacillales are known for their entomopathogenic activity, we focused our study on strains belonging to the Firmicutes phylum, corresponding to 14 of the isolated strains that have been deposited in the CSUR collection of IHU Mediterranée Infection. (Table 1). 
Table 1. Isolated strains and their identification.

\begin{tabular}{|c|c|c|c|c|c|}
\hline Phylum & Order & Genus-Species & $\begin{array}{l}\text { Strain } \\
\text { Name }\end{array}$ & $\begin{array}{l}\text { CSUR Collection } \\
\text { Number }\end{array}$ & $\begin{array}{c}\text { MALDI-TOF } \\
\text { Score Value }\end{array}$ \\
\hline \multirow{14}{*}{ Firmicutes } & \multirow{13}{*}{ Bacillale } & Bacillus clausii & 33 gite & Q3263 & 2.224 \\
\hline & & Bacillus licheniformis & 45 gite & Q3264 & 2.19 \\
\hline & & & 139 gite & Q3262 & 2.483 \\
\hline & & Bacillus sonorensis & 46 gite & Q3261 & 2.310 \\
\hline & & Bacillus mojavensis & 133 gite & Q3258 & 2.402 \\
\hline & & Bacillus cereus complex & 117 gite & Q3259 & 2.095 \\
\hline & & Bacillus cereus complex & 156 gite & Q3265 & 2.135 \\
\hline & & Bacillus cereus complex & 125 gite & Q3260 & 2.063 \\
\hline & & Brevibacillusborstelensis & 12 gite & Q3257 & 2.493 \\
\hline & & Lysinibacillus fusiformis & 99 gite & Q3255 & 2.345 \\
\hline & & $\begin{array}{l}\text { Virgibacillus } \\
\text { pantothenticus }\end{array}$ & 91 gite & Q3256 & 2.129 \\
\hline & & $\begin{array}{c}\text { Aneurinibacillus } \\
\text { migulanus }\end{array}$ & 126 gite & Q3254 & 2.474 \\
\hline & & $\begin{array}{l}\text { Paenibacillus } \\
\text { thiaminolyticus }\end{array}$ & 136 gite & Q3253 & 2.035 \\
\hline & Selenomonadales & $\begin{array}{c}\text { Dialister } \\
\text { propionicifaciens }\end{array}$ & 172 gite & Q3287 & 2.432 \\
\hline
\end{tabular}

After identification by MALDI-TOF MS (Matrix Assisted Laser Desorption Ionization-Time of Flight), the dendrogram (Figure 1) based on the protein profiles of the bacterial strains as well as 16S rRNA gene phylogeny showed that six strains from the group B. cereus complex, are grouped in three different clusters (Figure 2). Only one strain from each cluster was tested for insecticidal activity in order to avoid redundancy.

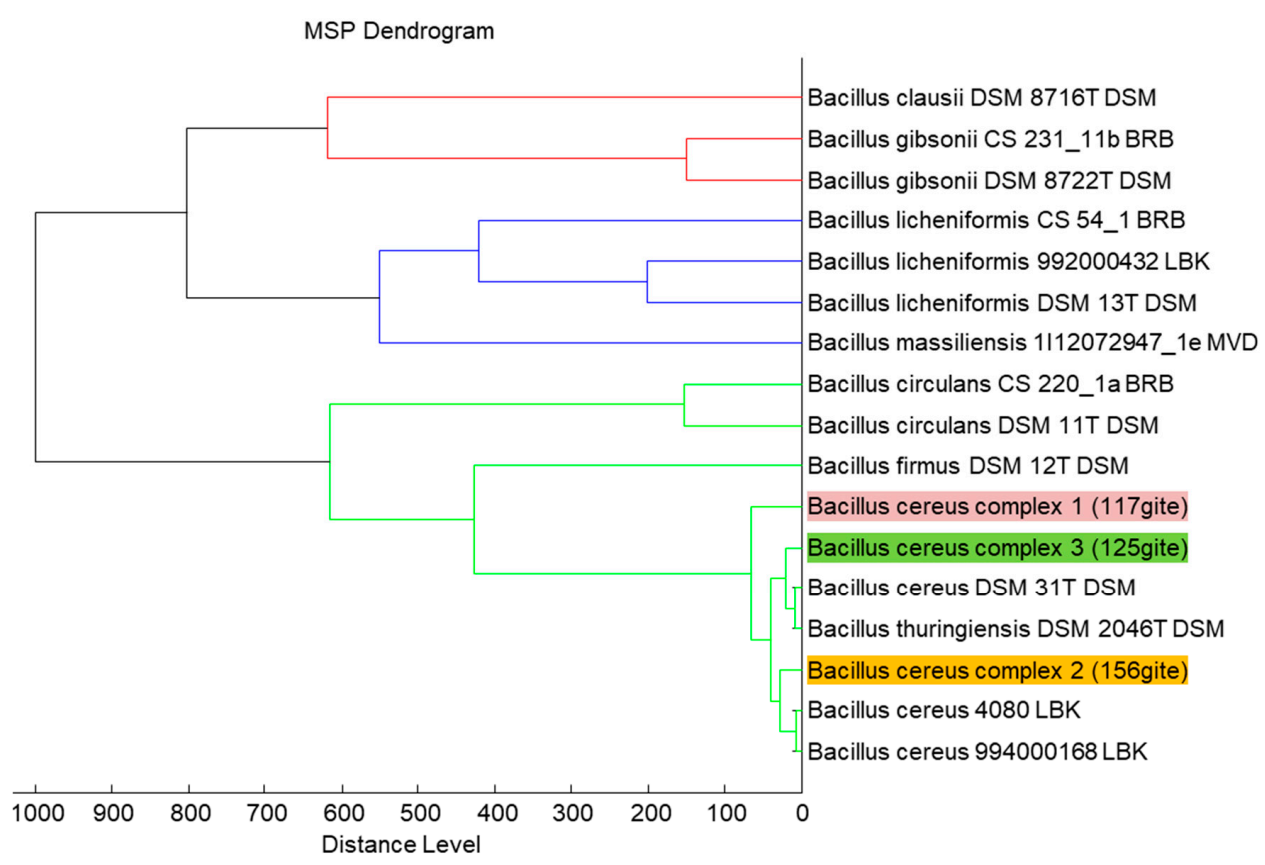

Figure 1. Dendrogram of Bacillus spp. strains representing the three clusters of B. cereus complex generated using the MALDI Biotyper 3.0 software (Bruker Daltonics, Bremen, Germany) with other Bacillus spp. as the outgroup. 


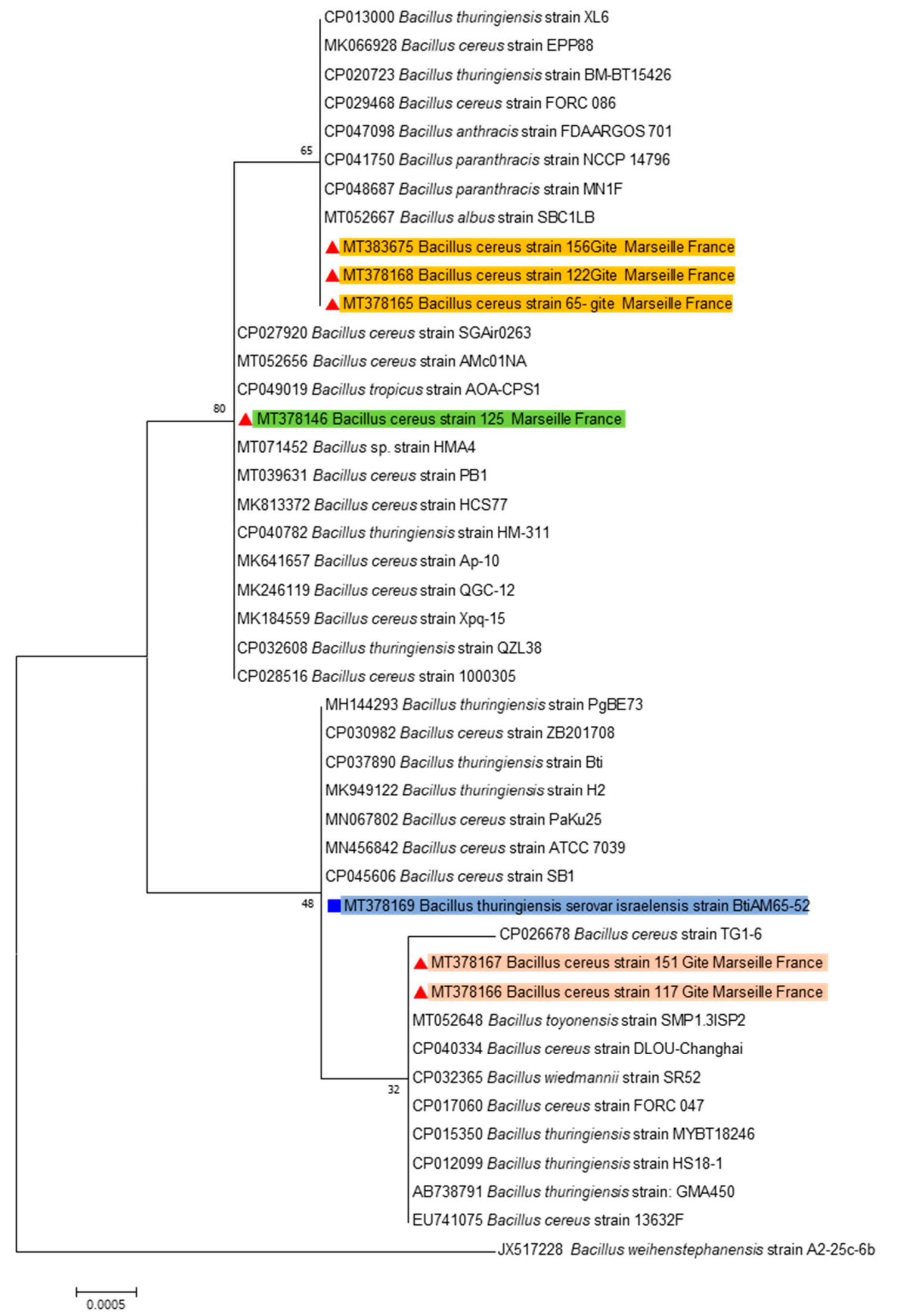

Figure 2. Maximum-likelihood phylogenetic tree of Bacillus spp., representing the three clusters of the B. cereus complex and including the Bti AM65-52 based on long 16S RNA gene (1500-bp). 


\subsection{Insecticidal Activity Prediction}

In the strain Bti AM65-52 (used as a control strain), all genes were detected. Most of the genes were absent in the strains we isolated. Only the gene cyt1C was detected in the strain 156 gite of the $B$. cereus complex together with the accessory genes p19 and p20. Strain 125 gite of the B. cereus complex showed the presence of only the accessory genes p19 and p20, while in the strain 117 gite, we only detected the accessory gene p19.

\subsection{Screening for Insecticidal Activity}

Of the bacterial strains isolated, 14 showed insecticidal activity. The mortality rises with the concentration. With the concentration $6 \mathrm{mg} / \mathrm{L}$ at $72 \mathrm{~h}$ post-administration, both for the supernatant and pellet fractions, $11 / 14$ of the strains were active against the $A$. albopictus larvae: a total of 10/14 with the supernatant fractions and 1/14 with the pellet fraction (Table 2).

Table 2. Detailed results of insecticidal activity exhibition of the secondary metabolites on 3rd and early 4 th instar A. albopictus larvae at $72 \mathrm{~h}$ post-administration.

\begin{tabular}{|c|c|c|c|c|c|}
\hline \multirow{2}{*}{ Strain } & \multirow{2}{*}{ Code } & \multirow{2}{*}{$\frac{\text { Pellet }}{(6 \mathrm{mg} / \mathrm{L}) *}$} & \multicolumn{2}{|c|}{ Supernatant } & \multirow{2}{*}{$\begin{array}{l}\text { Supernatant }+ \\
\text { Pellet }(6 \mathrm{mg} / \mathrm{L})\end{array}$} \\
\hline & & & $2 \mathrm{mg} / \mathrm{L}$ & $6 \mathrm{mg} / \mathrm{L}$ & \\
\hline B. cereus Complex 3 & 125 gite & $0 \%$ & $88 \%$ & $94 \%$ & $84 \%$ \\
\hline L. fusiformis & 99 gite & $0 \%$ & $47 \%$ & $85 \%$ & $76 \%$ \\
\hline B. cereusComplex 1 & 117 gite & $0 \%$ & $65 \%$ & $80 \%$ & $88 \%$ \\
\hline V. pantothenticus & 91 gite & $0 \%$ & $61 \%$ & $79 \%$ & $84 \%$ \\
\hline B. clausii & 33 gite & $0 \%$ & $48 \%$ & $75 \%$ & $84 \%$ \\
\hline B. licheniformis & 45 gite & $0 \%$ & $60 \%$ & $71 \%$ & $92 \%$ \\
\hline D. propionicifaciens & 172 gite & $0 \%$ & $52 \%$ & $66 \%$ & $64 \%$ \\
\hline B. cereus Complex 2 & 156 gite & $0 \%$ & $15 \%$ & $56 \%$ & $64 \%$ \\
\hline A. migulanus & 126 gite & $56 \%$ & $0 \%$ & $5 \%$ & $52 \%$ \\
\hline B. sonorensis & 46 gite & $0 \%$ & $24 \%$ & $51 \%$ & $56 \%$ \\
\hline B. licheniformis & 139 gite & $0 \%$ & $16 \%$ & $37 \%$ & $40 \%$ \\
\hline B. borstelensis & 12 gite & $0 \%$ & $15 \%$ & $19 \%$ & $16 \%$ \\
\hline P. thiaminolyticus & 136 gite & $0 \%$ & $0 \%$ & $01 \%$ & $00 \%$ \\
\hline B. mojavensis & 133 gite & $0 \%$ & $0 \%$ & $0 \%$ & $0 \%$ \\
\hline Bti & AM65-52 & $0 \%$ & $15 \%$ & $33 \%$ & $34 \%$ \\
\hline
\end{tabular}

*: Both of the concentrations were used. The results reported are those of $6 \mathrm{mg} / \mathrm{L}$.

The most active strain using the supernatant fractions was the 125 gite strain of the $B$. cereus complex with $94 \%$ larvae mortality. It was followed by L. fusiformis with $85 \%$ of mortality and then by the strain 117 gite of the B. cereus complex with $80 \%$ and $V$. pantothenticus with $79 \%$ of larvae mortality. B. clausii, B. licheniformis 45 gite and D. propionicifaciens were active with respectively $75 \%, 71 \%$ and $66 \%$ larvae mortality followed by the strains 156 gite of B. sonorensis and B. licheniformis 143 gite with respectively $56 \%, 51 \%$ and $37 \%$. Only one strain, $A$. migulanus, gave larvae mortality with the pellet fraction, with around $56 \%$.

The larvae mortality rate does not change significantly with the mixture of the pellet and supernatant fractions (X2 $=1.2194$ and $p=0.2694)$ (Table 2$)$.

Three strains were not active or had low activity against the mosquito larvae, resulting in less than $20 \%$ of mortality: B. borstelensis with $19 \%$, P. thiaminolyticus with $1 \%$ and B. mojavensis with $0 \%$.

We performed the comparison of the difference by pairs including the reference strain (Table S1) and found that the difference was significant (critical value of $\mathrm{khi}^{2}=23,685, p$-value $\leq 0.0001$ ) between the insecticidal activity exhibition rates of the supernatant fractions from the different strains at $72 \mathrm{~h}$ with $6 \mathrm{mg} / \mathrm{L}$. A difference is considered statistically significant when the $p$-values is $\leq 0.05$. The efficacy of the strains was compared with that of the Bti-positive control (Table 3). Using the Dunn test, the strains were classified into seven groups according to their efficiencies (Paris, France, https://www.xlstat.com). 
The group $\mathrm{G}$ is the most effective, composed of six strains that had $2 \mathrm{X}$ the activity of the positive control "mean ranks = [907 to 1079.5]", B. cereus Complex 3125 gite, L. fusiformis, B. cereus Complex1 117 gite, V. pantothenticus, B. clausii and B. licheniformis 45 gite. Meanwhile, the group A is the least effective group and is composed of the lowest and non-effective strains (Table S1) "mean ranks = [374.5 to 517]".

Table 3. The efficacy of the strains is compared with that given by the positive control Bti.

\begin{tabular}{ccccccc}
\hline Strain & Code & $\begin{array}{c}\text { Mortality } \\
\text { Rate 6 } \mathbf{~ m g / L ~}\end{array}$ & STDEV & Mean Rank & $p$-Value & Decision \\
\hline Bti & AM65-52 & $\mathbf{3 3 \%}$ & Ref & Ref & Ref & Ref \\
\hline B. cereus Complex 3 & 125 gite & $94 \%$ & 0.239 & -457.5 & $\leq 0.0001$ & Pos. S* \\
L. fusiformis & 99 gite & $85 \%$ & 0.359 & -390 & $\leq 0.0001$ & Pos. S* \\
B. cereus Complex 1 & 117 gite & $80 \%$ & 0.402 & -352.5 & $\leq 0.0001$ & Pos. S* \\
V. pantothenticus & 91 gite & $79 \%$ & 0.409 & -345 & $\leq 0.0001$ & Pos. S* \\
B. clausii & 33 gite & $75 \%$ & 0.435 & -315 & $\leq 0.0001$ & Pos. S* \\
B. licheniformis & 45 gite & $71 \%$ & 0.456 & -285 & $\leq 0.0001$ & Pos. S* \\
D. propionicifaciens & 172 gite & $66 \%$ & 0.476 & -247.5 & $\leq 0.0001$ & Pos. S* \\
B. cereus Complex 2 & 156 gite & $56 \%$ & 0.499 & -172.5 & 0.001 & Pos. S* \\
A. migulanus & 126 gite & $56 \%$ & 0.499 & -172.5 & 0.001 & Pos. S* \\
B. sonorensis & 46 gite & $51 \%$ & 0.502 & -135 & 0.011 & Pos. S* \\
B. licheniformis & 139 gite & $37 \%$ & 0.485 & -30 & 0.572 & NS *** \\
B. borstelensis & 12 gite & $19 \%$ & 0.394 & 105 & 0.048 & Neg. S** \\
P. thiaminolyticus & 136 gite & $01 \%$ & 0.1 & 240 & $\leq 0.0001$ & Neg. S ** \\
B. mojavensis & 133 gite & $0 \%$ & 0 & 247.5 & $\leq 0.0001$ & Neg. S** \\
\hline
\end{tabular}

${ }^{*}$ Pos. S: positively significant; ${ }^{* *}$ Neg. S: negatively significant; ${ }^{* * *}$ NS: non-significant; STDEV: standard deviation.

Ten strains were significantly $(p<0.0001-0.011)$ more active by killing more than $51 \%$ of $A$. albopictus larvae compared with the reference strain of Bti (33\%) (groups C, D, E, F and G), while one strain was non-significantly active $(p<0.572)$, killing $37 \%$ of larvae, therefore forming group $C$ with BtiAM65-52 (Table 3).

\section{Discussion}

In a recent study investigating the microbiota of four breeding sites in the Amazon basin in Brazil, a high diversity of bacteria was found and all sites were $94 \%$ dominated by Proteobacteria and Firmicutes [17]. Most species belonging to these phyla may be entomopathogenic, especially of the Bacillales order.

Interesting secondary metabolites were isolated from bacteria and exhibited the highest insecticidal activity, such as phthalic acid from the culture extract of Photorhabdus temperata M1021 [18].

We explored the presence of $c y t$ and cry genes including accessory genes encoding dipteran-specific endotoxins for the insecticidal activity prediction using a set of recently designed primers (Table 4). The commercialized strain Bti (strain AM65-52) was confirmed to carry all these genes. Most of these genes are absent in the strains we isolated. Despite the high insecticide activity displayed by all three $B$. cereus complex strains, only one gene $(c y t 1 C)$ was detected in the strain 156 gite of the B. cereus complex in addition to the accessory genes $p 19$ and $p 20$, so insecticidal activity is expected in this strain. In the strain gite 125, we detected only the accessory genes $p 19$ and $p 20$, while in the strain gite 117, we detected only the accessory gene $p 19$. In this case, insecticidal activity was not expected in these strains and revealed that toxicity can partially be explained by the presence of other endotoxins [16].

The insecticidal activity increased with the higher concentration of bacterial products. A small difference was found between the effect induced by the supernatant only, or the mixture of the supernatant and pellet fractions. The small increase may be induced by active compounds trapped inside the cells and released after the inactivation of the pellet.

VectoBac GR based essentially on Bti AM65-52 is the only product to complete the World Health Organization Pesticide Evaluation Scheme (WHOPES). The strain BtiAM65-52 was isolated from 
the product and was then tested to confirm our protocol and to asses our strains' effectiveness. Its pellet was inactive against $A$. albopictus larvae, while its supernatant fractions at $6 \mathrm{mg} / \mathrm{L}$ gives $33 \%$ of larvae mortality. We used only $6 \mathrm{mg} / \mathrm{L}$ of concentrated sterile culture medium to avoid banal bacterial multiplication in the flasks containing the larvae. Shorter durations and the highest effectiveness must be obtained by the highest concentrations.

Indeed, a large number of studies have been conducted on large collections of Bacillus strains to explore their biological activities, including antibacterial, insecticidal and other biological activities [13-16], for the interests they present such as the antimicrobial substances produced by $B$. licheniformis, B. pumilus, B. circulans, B. cereus, Brevibacillus laterosporus, Paenibacillus polymyxa and other species [19], or secreted toxins and insecticidal proteins [16]. Several other Bacillus spp. exhibited high toxicity against dipterans such as B. circulans [20] and Brevibacillus laterosporus [21,22].

Three tested strains of the B. cereus complex (Figure 2) provided a very high larvae mortality rate. This potent insecticidal activity may be induced by new endotoxins as long as the genes coding for known toxins are not detected in these strains. Several studies exploring Bacillus collections reported new strains [16]. Moreover, there can be five or six plasmids in some single B. thuringiensis strains, which can encode different toxin proteins [23].

L. fusiformis [24] is a Bacillus-like bacterium belonging to the family Bacillaceae and considered a naturally occurring bacterium, which can be isolated from several environmental samples, such as plants, soil and a few animals [25]. Numerous other interesting Lysinibacillus spp. were well-described such as L. xylanilyticus [26] and L. sphaericus [27]. We tested the supernatant and pellet fraction of L. fusiformis that we isolated from the larvae breeding site. The pellet fraction was not active, while the supernatant fraction kills $85 \%$ of the A. albopictus larvae. Some studies have reported the biological effects of L. fusiformis, such as antibacterial activity against resistant microorganisms, and the increasing complexity of biofilms [28,29]. However, in our study, we screened its secondary metabolites for insecticidal activity for the first time.

$V$. pantothenticus is a Gram-positive, spore-forming, aerobic, mesophilic and halotolerant bacterium [30]. This strain has never been explored for potent biological activities in order to be used for strategic intentions. We tested its supernatant and pellet fraction against the A. albopictus larvae and found that, interestingly, the supernatant fraction kills $79 \%$ of the third and early fourth larvae instars, while the pellet was not active. This strain must be further explored for other biological properties and advanced studies are needed to characterize the active compound against the mosquito larvae.

B. clausii is a non-pathogenic, spore-forming, aerobic, Gram-positive bacterium which is found to be beneficial to humans [31]. More precisely, it is effective and safe in the treatment and prevention of acute diarrhea without causing any adverse effects and is actually used as a probiotic [32]. Moreover, some strains were found to release antimicrobial substances active against Staphylococcus aureus, Enterococcus faecium and Clostridium difficile [33]. For the first time in 2015, cyclic lipopeptides produced by $B$. clausii DTM1, exhibited herbicidal activity in addition to insecticidal activity against aphid species Plutella xylostella and Diabrotica balteata [34]. Further, the strain BS02 was active against pulse beetle and mealybug [35]. We isolated a strain of B. clausii from the larvae breeding site and, when tested on the mosquito larvae, its supernatant fraction exhibited a high insecticidal activity with $75 \%$ of larva mortality. For the first time, B. clausii was shown to be insecticide against mosquito larvae and further studies need be conducted to determine whether the components already identified are responsible for the mosquito larval mortality or if other probably new molecules are the origin. Its insecticidal activity against the larvae of other species of mosquitoes of medical and veterinary interest is to be expected.

Since a long time, B. licheniformis strains are known as a source of carbohydrase and protease enzyme preparations used in food processing and form an attractive host for the expression of cloned gene products on an industrial scale [36]. Recently, numerous novel properties were found in some strains, such as the production of antifungal proteins for the biocontrol of plant diseases [37] and their use for crop improvement [38], in addition to the bioremediation of malathion-contaminated soil [39]. We isolated two strains of B. licheniformis from the larvae breeding site and when tested 
on mosquito larvae, their pellets were not active, while their supernatant fractions activities were significantly higher for the strain 45 gite with 71\% larvae mortality, in contrary to the strain 139 gite, which killed $37 \%$ of the A. albopictus larvae. Only few projects studied B. licheniformis in insect pest control. In 2003, some strains were transformed to express $B$. thuringiensis $\delta$-endotoxin $c r y 1 A b$ gene [40]. Furthermore, a newly discovered crystalline inclusion, that closely resembles the parasporal crystals of $B$. thuringiensis, suggests that it could be a gene transfer to them from $B$. thuringiensis [41]. The same study suggests that $B$. licheniformis adapts better naturally in phylloplane and that if potential insecticidal properties are discovered from $B$. licheniformis, they will make better candidates for insect biocontrol. To the best of our knowledge, our study is the first to identify the insecticidal properties of B. licheniformis' secreted metabolites. These mosquitocidal compounds must be identified in future studies in order to be used for A. albopictus-borne diseases control, but also to be tested on other mosquito species and insect pests.

D. propionicifaciens is a Gram-negative, non-motile, non-sporulating bacterium with a convoluted cell surface, which was described for the first time in 2005 [42]. We isolated this strain from the larvae breeding site despite being often found in clinical samples. We found that the supernatant fraction of $D$. propionicifaciens exhibited a significant and good insecticidal activity with $66 \%$ larvae mortality, although very few data are available on this bacterium.

Aneurinibacillus is a genus uniting aerobic, rod-shaped, endospore-forming bacteria [43]. A. migulanus is a soil-borne species which is known for its abilities to control plant disease development through the production of the cyclic peptide gramicidin $S$ and new gramicidin secondary metabolites, increasing its biocontrol activity, and a form a biosurfactant, reducing the surface wetness of plants [44-46]. Moreover, it could play a vital role in degrading chemical insecticide profenofos in soil [47]. However, to our knowledge, it has never been studied to identify insecticidal compounds. We tested the secondary metabolites of the A. migulanus strain we isolated and found that the pellet fraction exhibited a good larvicidal activity corresponding to either the inclusions inside the bacterium or to the constituents of the cells that we released during the pellet inactivation. In our study, $A$. migulanus is the unique strain that exhibited $A$. albopictus larvae mortality by its pellet faction and not with the supernatant, suggesting that it probably does not secrete secondary metabolites with insecticidal activity. Advanced studies are needed to look for the larvicide compound.

B. sonorensis is a rod-shaped, Gram-positive, motile and spore forming bacterium [48]. Very little information is available about this bacterium, although its lipase from a marine strain is used as an additive in detergent formulation [49]. We were interested to test the strain we isolated for insecticidal activity. The pellet fraction is not active against the A. albopictus larvae, while the supernatant fraction exhibited a good insecticidal activity, killing off $51 \%$. The properties of this bacterium are not well-known. We have identified for the first time a strain of B. sonorensis that produces insecticidal compounds which we need to explore further to characterize them.

Three of the strains we tested did not show insecticidal activity with either the pellet or the supernatant fraction: B. borstelensis, P. thiaminolyticus and B. mojavensis.

$B$. borstelensis is involved in the degradation of the herbicide sulfosulfuron and the biodegradation of polyethylene, useful for future environmental/biotechnological applications. [50-52]. In this study, we tested it for the first time for insecticidal activity and it was found to exhibit a low effect against $A$. albopictus larvae.

P. thiaminolyticus is a Gram-positive, aerobic bacterium which is related to Bacilli and identified as a new cause of human infections [53]. Some Paenibacillus species had an insecticidal effect against the larvae of pest insects $[53,54]$. We isolated a strain of $P$. thiaminolyticus and tested its supernatant and pellet fractions against $A$. albopictus larvae. No insecticidal activity was found against $A$. albopictus larvae.

B. mojavensis is known for its antimicrobial properties and plant growth promotion [55-57], but it has never been tested before for the production of insecticidal compounds.

In conclusion, we explored the observed natural phenomenon of high mortality in a larvae breeding site. We isolated bacteria strains that exhibit the highest insecticidal activity compared with 
a commercial bacterial insecticide product (Bti) and we concluded that most probably one/several of the isolated bacteria may be responsible for the observed mortality. For most strains, this was the first time they were tested against mosquito larvae. In addition, the insecticidal activity of their separated supernatant and pellet fractions is reported for the first time. Advanced analyses and further studies are needed to characterize the insecticidal compounds and mechanisms of action. It will be of great importance to test them against other important insects of medical, veterinary and agricultural interest in order to use them in the control of biological vectors.

\section{Materials and Methods}

\subsection{Bacteria Isolation}

Twenty (20) natural mosquito breeding sites were explored in May 2019 in the city of Marseille, France, looking for the presence of larvae, pupa or cocoons that would indicate the presence of dead or mal-formed mosquito larvae. A phenomenon of natural mortality was observed in one larva breeding site, where hundreds of dead Aedes albopictus mosquito larvae (1st and 2nd instars) were observed in a garden that had never been treated with insecticides. This breeding site was located in an empty aquarium with the rest of a degraded peat moss. Other breeding sites were identified in the same garden without associated mortality. The content of the mortality-associated larval breeding site was then recovered, homogenized and, thereafter, ten serial dilutions were made to obtain 1/10. The inoculum $(50 \mu \mathrm{L})$ was seeded on Columbia agar supplemented with $5 \%$ sheep blood (bioMérieux, Marcy l'Etoile, France) and incubated under aerophilic conditions at $37^{\circ} \mathrm{C}$ for at least $24 \mathrm{~h}$.

\subsection{Strains Identification}

Bacterial species were directly identified from each bacterial colony using matrix-assisted laser desorption ionization-time mass spectrometry (MALDI-TOF MS) (Bruker Daltonics, Bremen, Germany) [58] following the same protocol as previously described by Seng et al. [59] with a Microflex spectrometer (Bruker Daltonics, Leipzig, Germany). A score of $>2$ allowed identification at the species level, and a score of $<1.7$ was considered as insufficient for the identification at the species level. In this case, 16S rRNA gene was amplified and the amplicon was sequenced. Briefly, DNA extraction was performed using EZ1 DNA kits (Qiagen, Courtaboeuf, France), according to the manufacturer's protocol. Amplification and sequencing were performed as described in the study by Dahmana et al. [60] using 16S universal primers [61]. The obtained electropherograms were assembled and edited using the ChromasPro1.7.7 software (Technelysium Pty Ltd., Tewantin, Australia), and then the sequences obtained were compared with those available in the GenBank database by NCBI BLAST (http://blast.ncbi.nlm.nih.gov/Blast.cgi).

\subsection{Fractions Preparation}

\subsubsection{Bacteria Culture}

Bacillus spp. strains were stored at $-80^{\circ} \mathrm{C}$. The culture was carried out on solid medium Columbia agar $+5 \%$ sheep blood (bioMérieux, Marcy 1'Etoile, France) under aerobic conditions at $37^{\circ} \mathrm{C}$. Confirmation of species identification was made by MALDI-TOF MS. Thereafter, several colonies were transferred in a sterile condition in 1 litter of liquid medium Tryptic soy broth T8907-1KG (Sigma-Aldrich, Saint-Quentin-Fallavier, France), and were incubated for three days at $37^{\circ} \mathrm{C}$ and $110 \mathrm{rpm}$ in a shaker incubator under aerobic conditions. A negative culture control (sterile, bacteria-free medium stored behind the other culture flasks) was performed and regularly checked for clouding, which indicates contamination, and a clear broth after 3 days of incubation confirmed the absence of contamination.

The supernatant-pellet separation was carried out by centrifugation at $8000 \mathrm{~g}$ for $20 \mathrm{~min}$ at $4{ }^{\circ} \mathrm{C}$ using A98813 Bottle Assembly, J-Lite PP with a JLA-8.1000 rotor (Beckman Coulter, Villepinte, France). 
After centrifugation, the supernatant was immediately filtrated at $0.45 \mu \mathrm{m}$ and then disposed in $75 \mathrm{~mL}$ flasks and frozen horizontally at $-80^{\circ} \mathrm{C}$ and lyophilized the next day. The lyophilizate was stored at $-20{ }^{\circ} \mathrm{C}$ until further assays.

\subsubsection{Releasing Inclusions and Main Cell Components}

The pellet was resuspended in PBS and then distributed in $2 \mathrm{~mL}$ cryotubes (Bio-One GmbH, Kremsmünster, Austria). Each tube was subjected to 3 freeze-thaw cycles for 5 min using liquid nitrogen and a hybridization incubator heated to $50{ }^{\circ} \mathrm{C}$. The tubes are centrifuged at $13,000 \mathrm{G}$ for $10 \mathrm{~s}$ and the contents are transferred into Eppendorf Safe-Lock Tubes, $1.5 \mathrm{~mL}$ (Eppendorf Quality ${ }^{\mathrm{TM}}$, Montesson, France) and then subjected to 3 sonication cycles at $50 \mathrm{~Hz}$ amplitude for $30 \mathrm{~s}$. Subsequently, ultracentrifugation is carried out at $20,000 \mathrm{G}$ for $20 \mathrm{~min}$ at $4{ }^{\circ} \mathrm{C}$. Thereafter, the supernatant is recovered and directly filtered at $0.45 \mu \mathrm{m}$ and stored at $-20^{\circ} \mathrm{C}$.

\subsubsection{Fractions Used in Larvae Assays}

Once the larvae were ready (3rd and early 4 th instars), the already prepared sterile fractions (pellet and supernatant) of a bacterium were thawed at room temperature and then the Bradford's protein test was performed. Subsequently, the volume of fraction administered to the larvae was calculated to have two concentrations of 2 and $6 \mathrm{mg} / \mathrm{L}$ in the final volume. The supernatant and pellet fractions of each stain were tested separately at 2 and $6 \mathrm{mg} / \mathrm{L}$ corresponding to small volumes of fractions administered to the larvae that did not promote common bacterial multiplication in the flask containing the larvae during the tests. We also tested the mix of the two fractions at $6 \mathrm{mg} / \mathrm{L}$ each to see if there is a synergetic effect of the secreted compounds and the cell constituents.

We used Bacillus thuringiensis subsp. israelensisAM65-52 isolated from a commercial granular formulation (VectoBac GR, Valent Bioscience, Libertyville, IL, USA) to check and validate our protocol and to assess our strains' insecticidal activity.

\subsection{Plasmid DNA Isolation and Investigation of Bacterial Genes Encoding Toxins}

Total plasmid DNA was isolated from the strains belonging to the B. cereus complex using a Smart-Pure plasmid kit (Eurogentec, Angers, France).

Plasmid DNA was used for the PCR to screen for the potential presence of genes encoding insecticidal proteins, such as Cry and Cyt (Table 4). The PCR amplifications were thus performed [62]. We took the Bti AM65-52 as a positive control.

Table 4. List of primers used in this study to explore the presence of genes encoding endotoxin, accessory proteins and Cyt.

\begin{tabular}{|c|c|c|c|c|}
\hline Gene & Primers & Sequences & Amplicon Size & References \\
\hline \multirow{2}{*}{ cry $4 a / 4 b$} & $\operatorname{dip} 2 a$ & GGTGCTTCCTATTCTTTGGC & \multirow{2}{*}{$1290 \mathrm{bp}$} & \multirow{2}{*}[63]{} \\
\hline & dip1b & ATGGCTTGTTTCGCTACATC & & \\
\hline \multirow{2}{*}{ cry10 } & cry10-1 & ATATGAAATATTCAATGCTC & \multirow{2}{*}{$614 \mathrm{bp}$} & \multirow{2}{*}[64]{} \\
\hline & cry10-2 & ATAAATTCAAGTGCCAAGTA & & \\
\hline \multirow{2}{*}{ cry11 } & cry11-1 & TTAGAAGATACGCCAGATCAAGC & \multirow{2}{*}{$304 \mathrm{bp}$} & \multirow{2}{*}{ [10] } \\
\hline & cry11-2 & CATTTGTACTTGAAGTTGTAATCCC & & \\
\hline \multirow{2}{*}{ cyt1a } & cyt1A1 & GTTGTAAGCTTATGGAAAAT & \multirow{2}{*}{$701 \mathrm{bp}$} & \multirow{2}{*}[65]{} \\
\hline & cyt1A2 & TTAGAAGCTTCCATTAATA & & \\
\hline \multirow{2}{*}{ cyt1c } & cyt1C1 & CAAAATCTACGGGAGCAAGG & \multirow{2}{*}{$1320 \mathrm{bp}$} & \multirow{2}{*}{ [16] } \\
\hline & cyt1C2 & GGAAGGATCCCTTTGACTTTT & & \\
\hline
\end{tabular}


Table 4. Cont.

\begin{tabular}{|c|c|c|c|c|}
\hline Gene & Primers & Sequences & Amplicon Size & References \\
\hline \multirow[t]{2}{*}{ cyt $2 a$} & cyt2A1 & AATACATTTCAAGGAGCTA & \multirow{2}{*}{$471 \mathrm{bp}$} & \multirow{2}{*}[66]{} \\
\hline & cyt2A2 & TTTCATTTTAACTTCATATC & & \\
\hline \multirow{2}{*}{ p19 } & p19-1 & GCAGGAGGAACATCACCATT & \multirow{2}{*}{$291 \mathrm{bp}$} & \multirow{2}{*}{ [16] } \\
\hline & p19-2 & GGATTTGCTGAGCAGGTCAT & & \\
\hline \multirow{2}{*}{$p 20$} & p20-1 & TGACGAGGAAACAGAGTATACGA & \multirow{2}{*}{$704 \mathrm{bp}$} & \multirow{2}{*}{ [16] } \\
\hline & p20-2 & TGAAAGGTTAAACGTTCCGATT & & \\
\hline
\end{tabular}

\subsection{Screening for Insecticidal Activity}

Aedes albopictus colonies were maintained at $27 \pm 0.5^{\circ} \mathrm{C}$ and $80 \pm 5 \%$ relative humidity. Adult mosquitoes were maintained on a constant exposure to $10 \%$ sucrose presented through cotton balls changed daily. For egg production, adult female mosquitoes were offered defibrinated human blood (French blood agency, Marseille, France) via a Hemotek membrane feeding system. Larvae were fed Tetra-Min fish food in clear water until the pupal stage.

Seventy-five $\mathrm{mL}$ flasks were used for the insecticide screening assays. Twenty-five of the 3rd and early 4th larvae instars were pouted in $100 \mathrm{~mL}$ of clear water. All the fractions tests were performed on 25 larvae $(\mathrm{N}=4)$, for a total of 100 larvae as recommended by WHO [67]. Immediately after separating larvae in flasks containing $99 \mathrm{~mL}$ of clean distilled water, we added the calculated volume. Larvae were maintained at $27 \pm 0.5^{\circ} \mathrm{C}$ and not fed until the 24th $\mathrm{h}$. Dead larvae were counted at 24,48 and $72 \mathrm{~h}$. In each test, 100 larvae were used as a negative control that received no fraction, to eventually assess natural mortality. A strain was considered to have a good effect if it caused $20 \%$ mortality.

\subsection{Statistical Analysis}

The Epi Info version 7 program (http://www.cdc.gov/epiinfo/index.html), (Addinsoft 2019) and the XLSTAT statistical and data analysis solution (https://www.xlstat.com) were used to compare mortality rates recorded at $72 \mathrm{~h}$ after the administration of $6 \mathrm{mg} / \mathrm{L}$ of the supernatant fractions. The Kruskal-Wallis test, comparison of $\mathrm{k}$ proportions and pairwise comparison were realized. A difference was statistically significant when $p$-values were $\leq 0.05$. The Dunn procedure (Bilateral test) was performed to separate groups of strains according to their efficiencies.

Supplementary Materials: The following are available online at http://www.mdpi.com/2076-0817/9/6/486/s1, Table S1: Dunn pairwise test's results. Comparison of insecticidal activity rates between the different isolated strains and Bti (AM65-52).

Author Contributions: H.D.: Conceptualization, methodology; investigation; software; writing-original draft preparation; D.R.: Conceptualization; methodology; writing-review and editing. F.F.: Methodology; validation; writing - review and editing; supervision. O.M.: Conceptualization; methodology; validation; writing—review and editing; supervision. All authors have read and agreed to the published version of the manuscript.

Funding: This study was supported by the Institut Hospitalo-Universitaire (IHU) Méditerranée Infection, the National Research Agency under the program « Investissements d'avenir », reference ANR-10-IAHU-03.

Conflicts of Interest: The authors declare no conflict of interest. The funders had no role in study design, data collection, and analysis, decision to publish, or preparation of the manuscript.

\section{References}

1. Dhanasekaran, D.; Thangaraj, R. Microbial secondary metabolites are an alternative approaches against insect vector to prevent zoonotic diseases. Asian Pac. J. Trop. Dis. 2014, 4, 253-261. [CrossRef]

2. Trevors, J.T.; Barkay, T.; Bourquin, A.W. Gene transfer among bacteria in soil and aquatic environments: A review. Can. J. Microbiol. 1987, 33, 191-198. [CrossRef] 
3. Mishra, S.K.; Keller, J.E.; Miller, J.R.; Heisey, R.M.; Nair, M.G.; Putnam, A.R. Insecticidal and nematicidal properties of microbial metabolites. J. Ind. Microbiol. 1987, 2, 267-276. [CrossRef]

4. Kuta, F. Antifungal effect of Calotropis procera stem bark on Epidermophyton flocosum and Trichophyton gypseum. African J. Biotechnol. 2008, 7, 2116-2118.

5. Polanczyk, R.A.; van Frankenhuyzen, K.; Pauli, G. The american Bacillus thuringiensis based biopesticides market. In Bacillus Thuringiensis and Lysinibacillus Sphaericus: Characterization and Use in the Field of Biocontrol; Springer International Publishing: Cham, Switzerland, 2017; pp. 173-184. ISBN 9783319566788.

6. Dahmana, H.; Mediannikov, O. Mosquito-Borne Diseases Emergence/Resurgence and How to Effectively Control It Biologically. Pathogens 2020, 9, 310. [CrossRef] [PubMed]

7. Zhang, Q.; Hua, G.; Adang, M.J. Effects and mechanisms of Bacillus thuringiensis crystal toxins for mosquito larvae. Insect Sci. 2017, 24, 714-729. [CrossRef]

8. Palma, L.; Muñoz, D.; Berry, C.; Murillo, J.; Caballero, P. Bacillus thuringiensis toxins: An overview of their biocidal activity. Toxins 2014, 6, 3296-3325. [CrossRef]

9. Tilquin, M.; Paris, M.; Reynaud, S.; Despres, L.; Ravanel, P.; Geremia, R.A.; Gury, J. Long lasting persistence of Bacillus thuringiensis Subsp. israelensis (Bti) in mosquito natural habitats. PLoS ONE 2008, 3, e3432.

10. Bravo, A.; Sarabia, S.; Lopez, L.; Ontiveros, H.; Abarca, C.; Ortiz, A.; Ortiz, M.; Lina, L.; Villalobos, F.J.; Peña, G.; et al. Characterization of cry genes in a Mexican Bacillus thuringiensis strain collection. Appl. Environ. Microbiol. 1998, 64, 4965-4972. [CrossRef]

11. Par, P.; Paris, M.; Chevillon, C.; David, J.-P. Evolution de la résistance au bactério-insecticide Bti chez les moustiques. Ph.D. Thesis, Université de Grenoble, Grenoble, France, 2010.

12. Su, T. Resistance and Its Management to Microbial and Insect Growth Regulator Larvicides in Mosquitoes; IntechOpen: London, UK, 2016.

13. Amin, M.; Rakhisi, Z.; Zarei, A.A. Isolation and Identification of Bacillus Species From Soil and Evaluation of Their Antibacterial Properties. Avicenna J. Clin. Microb. Infect. 2015, 2, 23233. [CrossRef]

14. Tariq, A.L.; Sudha, S.; Reyaz, A.L. Isolation and Screening of Bacillus Species from Sediments and Application in Bioremediation. Int. J. Curr. Microbiol. Appl. Sci. 2016, 5, 916-924. [CrossRef]

15. Galarza-Seeber, R.; Latorre, J.D.; Hernandez-Velasco, X.; Wolfenden, A.D.; Bielke, L.R.; Menconi, A.; Hargis, B.M.; Tellez, G. Isolation, screening and identification of Bacillus spp. as direct-fed microbial candidates for aflatoxin B1 biodegradation. Asian Pac. J. Trop. Biomed. 2015, 5, 702-706. [CrossRef]

16. Nair, K.; Al-Thani, R.; Al-Thani, D.; Al-Yafei, F.; Ahmed, T.; Jaoua, S. Diversity of Bacillus thuringiensis Strains From Qatar as Shown by Crystal Morphology, $\delta$-Endotoxins and Cry Gene Content. Front. Microbiol. 2018, 9 , 708. [CrossRef] [PubMed]

17. Nilsson, L.K.J.; de Oliveira, M.R.; Marinotti, O.; Rocha, E.M.; Håkansson, S.; Tadei, W.P.; de Souza, A.Q.L.; Terenius, O. Characterization of Bacterial Communities in Breeding Waters of Anopheles darlingi in Manaus in the Amazon Basin Malaria-Endemic Area. Microb. Ecol. 2019, 1-11. [CrossRef]

18. Ullah, I.; Latif Khan, A.; Ali, L.; Khan, A.R.; Waqas, M.; Lee, I.-J.; Shin, J.-H. An Insecticidal Compound Produced by an Insect-Pathogenic Bacterium Suppresses Host Defenses through Phenoloxidase Inhibition. Molecules 2014, 19, 20913-20928. [CrossRef]

19. Foldes, T.; Banhegyi, I.; Herpai, Z.; Varga, L.; Szigeti, J. Isolation of Bacillus strains from the rhizosphere of cereals and in vitro screening for antagonism against phytopathogenic, food-borne pathogenic and spoilage micro-organisms. J. Appl. Microbiol. 2000, 89, 840-846. [CrossRef]

20. Darriet, F.; Hougard, J.-M. An isolate of Bacillus circulans toxic to mosquito larvae. J. Am. Mosq. Control. Assoc. 2002, 18, 65-67.

21. Favret, M.E.; Yousten, A.A. Insecticidal activity of Bacillus laterosporus. J. Invertebr. Pathol. 1985, 45, $195-203$. [CrossRef]

22. Orlova, M.V.; Smirnova, T.A.; Ganushkina, L.A.; Yacubovich, V.Y.; Azizbekyan, R.R. Insecticidal activity of Bacillus laterosporus. Appl. Environ. Microbiol. 1998, 64, 2723-2725. [CrossRef]

23. Aronson, A. Sporulation and delta-endotoxin synthesis by Bacillus thuringiensis. Cell. Mol. Life Sci. 2002, 59, 417-425. [CrossRef]

24. Ahmed, I.; Yokota, A.; Yamazoe, A.; Fujiwara, T. Proposal of Lysinibacillus boronitolerans gen. nov. sp. nov., and transfer of Bacillus fusiformis to Lysinibacillus fusiformis comb. nov. and Bacillus sphaericus to Lysinibacillus sphaericus comb. nov. Int. J. Syst. Evol. Microbiol. 2007, 57, 1117-1125. [CrossRef] [PubMed] 
25. Sulaiman, I.M.; Hsieh, Y.-H.; Jacobs, E.; Miranda, N.; Simpson, S.; Kerdahi, K. Identification of Lysinibacillus fusiformis Isolated from Cosmetic Samples Using MALDI-TOF MS and 16S rRNA Sequencing Methods. J. AOAC Int. 2018, 101, 1757-1762. [CrossRef] [PubMed]

26. Lee, C.S.; Jung, Y.-T.; Park, S.; Oh, T.-K.; Yoon, J.-H. Lysinibacillus xylanilyticus sp. nov., a xylan-degrading bacterium isolated from forest humus. Int. J. Syst. Evol. Microbiol. 2010, 60, 281-286. [CrossRef] [PubMed]

27. Berry, C. The bacterium, Lysinibacillus sphaericus, as an insect pathogen. J. Invertebr. Pathol. 2012, 109, 1-10. [CrossRef] [PubMed]

28. Abideen, S.; Babuselvam, M. Antagonistic activity of Lysinibacillus fusiformis $\mathrm{n} 139$ strain isolated from marine fish Triacanthus strigilifer and genome sequence. Int. J. Curr. Microbiol. Appl. Sci. 2014, 3, 1066-1072.

29. Gallegos-Monterrosa, R.; Kankel, S.; Götze, S.; Barnett, R.; Stallforth, P.; Kovács, Á.T. Lysinibacillus fusiformis M5 Induces Increased Complexity in Bacillus subtilis 168 Colony Biofilms via Hypoxanthine. J. Bacteriol. 2017, 199, e00204-17. [CrossRef]

30. Wang, J.-P.; Liu, B.; Liu, G.-H.; Chen, D.-J.; Zhu, Y.-J.; Chen, Z.; Che, J.-M. Genome Sequence of Virgibacillus pantothenticus DSM 26T (ATCC 14576), a Mesophilic and Halotolerant Bacterium Isolated from Soil. Genome Announc. 2015, 3, e01064-15.

31. Duc, L.H.; Hong, H.A.; Barbosa, T.M.; Henriques, A.O.; Cutting, S.M. Characterization of Bacillus probiotics available for human use. Appl. Environ. Microbiol. 2004, 70, 2161-2171. [CrossRef]

32. Ianiro, G.; Rizzatti, G.; Plomer, M.; Lopetuso, L.; Scaldaferri, F.; Franceschi, F.; Cammarota, G.; Gasbarrini, A. Bacillus clausii for the Treatment of Acute Diarrhea in Children: A Systematic Review and Meta-Analysis of Randomized Controlled Trials. Nutrients 2018, 10, 1074. [CrossRef]

33. Urdaci, M.C.; Bressollier, P.; Pinchuk, I. Bacillus clausii probiotic strains: Antimicrobial and immunomodulatory activities. J. Clin. Gastroenterol. 2004, 38, S86-S90. [CrossRef]

34. Guo, D.-L.; Wan, B.; Xiao, S.-J.; Allen, S.; Gu, Y.-C.; Ding, L.-S.; Zhou, Y. Cyclic Lipopeptides with Herbicidal and Insecticidal Activities Produced by Bacillus clausii DTM1. Nat. Prod. Commun. 2015, 10, 2151-2153. [CrossRef] [PubMed]

35. Hazra, C.; Kundu, D.; Chaudhari, A. Lipopeptide biosurfactant from Bacillus clausii BS02 using sunflower oil soapstock: Evaluation of high throughput screening methods, production, purification, characterization and its insecticidal activity. RSC Adv. 2015, 5, 2974-2982. [CrossRef]

36. de Boer, A.S.; Priest, F.; Diderichsen, B. On the industrial use of Bacillus licheniformis: A review. Appl. Microbiol. Biotechnol. 1994, 40, 595-598. [CrossRef]

37. Zhaolin, J.; Huiwen, H.; Huijuan, Z.; Feng, H.; Yunhui, T.; Zhengwen, Y.; Jingyou, X. The Biocontrol Effects of the Bacillus licheniformis W10 Strain and Its Antifungal Protein Against Brown Rot in Peach. Hortic. Plant. J. 2015, 1, 131-138.

38. Radhakrishnan, R.; Hashem, A.; Abd Allah, E.F. Bacillus: A Biological Tool for Crop Improvement through Bio-Molecular Changes in Adverse Environments. Front. Physiol. 2017, 8, 667. [CrossRef]

39. Khan, S.; Zaffar, H.; Irshad, U.; Ahmad, R.; Khan, A.; Shah, M.; Bilal, M.; Iqbal, M.; Naqvi, T. Biodegradation of malathion by Bacillus licheniformis strain ML-1. Arch. Biol. Sci. 2016, 68, 51-59. [CrossRef]

40. Theoduloz, C.; Vega, A.; Salazar, M.; Gonzalez, E.; Meza-Basso, L. Expression of a Bacillus thuringiensis delta-endotoxin cry1Ab gene in Bacillus subtilis and Bacillus licheniformis strains that naturally colonize the phylloplane of tomato plants (Lycopersicon esculentum, Mills). J. Appl. Microbiol. 2003, 94, 375-381. [CrossRef]

41. Yan, M.; Roehrl, M.H.; Wang, J.Y. Discovery of crystalline inclusions in Bacillus licheniformis that resemble parasporal crystals of Bacillus thuringiensis. Can. J. Microbiol. 2007, 53, 1111-1115. [CrossRef]

42. Jumas-Bilak, E.; Jean-Pierre, H.; Carlier, J.-P.; Teyssier, C.; Bernard, K.; Gay, B.; Campos, J.; Morio, F.; Marchandin, H. Dialister micraerophilus sp. nov. and Dialister propionicifaciens sp. nov., isolated from human clinical samples. Int. J. Syst. Evol. Microbiol. 2005, 55, 2471-2478. [CrossRef]

43. Shida, O.; Takagi, H.; Kadowaki, K.; Komagata, K. Proposal for Two New Genera, Brevibacillus gen. nov. and Aneurinibacillus gen. nov. Int. J. Syst. Bacteriol. 1996, 46, 939-946. [CrossRef]

44. Berditsch, M.; Afonin, S.; Ulrich, A.S. The ability of Aneurinibacillus migulanus (Bacillus brevis) to produce the antibiotic gramicidin S is correlated with phenotype variation. Appl. Environ. Microbiol. 2007, 73, 6620-6628. [CrossRef] [PubMed] 
45. Alenezi, F.N.; Rekik, I.; Bełka, M.; Ibrahim, A.F.; Luptakova, L.; Jaspars, M.; Woodward, S.; Belbahri, L. Strain-level diversity of secondary metabolism in the biocontrol species Aneurinibacillus migulanus. Microbiol. Res. 2016, 182, 116-124. [CrossRef] [PubMed]

46. Alenezi, F.N.; Rekik, I.; Chenari Bouket, A.; Luptakova, L.; Weitz, H.J.; Rateb, M.E.; Jaspars, M.; Woodward, S.; Belbahri, L. Increased Biological Activity of Aneurinibacillus migulanus Strains Correlates with the Production of New Gramicidin Secondary Metabolites. Front. Microbiol. 2017, 8, 517. [CrossRef] [PubMed]

47. Palanimanickam, A.; Sepperumal, U. Profenofos Degradation Potential of Bacillus cereus and Aneurinibacillus migulanus Isolated from Paddy Crop Field Soil. J. Pure Appl. Microbiol. 2017, 11, 221-227. [CrossRef]

48. Palmisano, M.M.; Nakamura, L.K.; Duncan, K.E.; Istock, C.A.; Cohan, F.M. Bacillus sonorensis sp. nov., a close relative of Bacillus licheniformis, isolated from soil in the Sonoran Desert, Arizona. Int. J. Syst. Evol. Microbiol. 2001, 51, 1671-1679. [CrossRef]

49. Nerurkar, M.; Joshi, M.; Pariti, S.; Adivarekar, R. Application of Lipase from Marine Bacteria Bacillus sonorensis as an Additive in Detergent Formulation. J. Surfactants Deterg. 2013, 16, 435-443. [CrossRef]

50. Arya, R.; Mishra, N.K.; Sharma, A.K. Brevibacillus borstelensis and Streptomyces albogriseolus have roles to play in degradation of herbicide, sulfosulfuron. 3 Biotech 2016, 6, 246. [CrossRef]

51. Hadad, D.; Geresh, S.; Sivan, A. Biodegradation of polyethylene by the thermophilic bacterium Brevibacillus borstelensis. J. Appl. Microbiol. 2005, 98, 1093-1100. [CrossRef]

52. Khalil, A.B.; Sivakumar, N.; Arslan, M.; Saleem, H.; Qarawi, S. Insights into Brevibacillus borstelensis AK1 through Whole Genome Sequencing: A Thermophilic Bacterium Isolated from a Hot Spring in Saudi Arabia. Biomed. Res. Int. 2018, 2018, 1-9. [CrossRef]

53. Ouyang, J.; Pei, Z.; Lutwick, L.; Dalal, S.; Yang, L.; Cassai, N.; Sandhu, K.; Hanna, B.; Wieczorek, R.L.; Bluth, M.; et al. Case report: Paenibacillus thiaminolyticus: A new cause of human infection, inducing bacteremia in a patient on hemodialysis. Ann. Clin. Lab. Sci. 2008, 38, 393-400.

54. Grady, E.N.; MacDonald, J.; Liu, L.; Richman, A.; Yuan, Z.-C. Current knowledge and perspectives of Paenibacillus: A review. Microb. Cell Fact. 2016, 15, 203. [CrossRef] [PubMed]

55. Choi, S.M.; Park, M.H.; Jung, T.S.; Moon, K.H.; Kim, K.M.; Kang, J.S. Characterization of Bacillus mojavensis KJS-3 for industrial applications. Arch. Pharm. Res. 2011, 34, 289-298. [CrossRef] [PubMed]

56. Kim, K.M.; Liu, J.; Go, Y.S.; Kang, J.S. Characterization of Bacillus mojavensis KJS-3 for the Promotion of Plant Growth. J. Life Sci. 2015, 25, 910-916. [CrossRef]

57. Jasim, B.; Sreelakshmi, S.; Mathew, J.; Radhakrishnan, E.K. Identification of endophytic Bacillus mojavensis with highly specialized broad spectrum antibacterial activity. 3 Biotech 2016, 6, 187. [CrossRef]

58. La Scola, B.; Raoult, D. Direct identification of bacteria in positive blood culture bottles by matrix-assisted laser desorption ionisation time-of-flight mass spectrometry. PLoS ONE 2009, 4, e8041. [CrossRef]

59. Seng, P.; Drancourt, M.; Gouriet, F.; La Scola, B.; Fournier, P.; Rolain, J.M.; Raoult, D. Ongoing Revolution in Bacteriology: Routine Identification of Bacteria by Matrix-Assisted Laser Desorption Ionization Time-of-Flight Mass Spectrometry. Clin. Infect. Dis. 2009, 49, 543-551. [CrossRef]

60. Dahmana, H.; Granjon, L.; Diagne, C.; Davoust, B.; Fenollar, F.; Mediannikov, O. Rodents as Hosts of Pathogens and Related Zoonotic Disease Risk. Pathogens 2020, 9, 202. [CrossRef]

61. La Scola, B.; Liang, Z.; Zeaiter, Z.; Houpikian, P.; Grimont, P.A.D.; Raoult, D. Genotypic characteristics of two serotypes of Bartonella henselae. J. Clin. Microbiol. 2002, 40, 2002-2008. [CrossRef]

62. Dahmana, H.; Amanzougaghene, N.; Davoust, B.; Normand, T.; Carette, O.; Demoncheaux, J.-P.; Mulot, B.; Fabrizy, B.; Scandola, P.; Chik, M.; et al. Great diversity of Piroplasmida in Equidae in Africa and Europe, including potential new species. Vet. Parasitol. Reg. Stud. Rep. 2019, 18, 100332. [CrossRef]

63. Carozzi, N.B.; Kramer, V.C.; Warren, G.W.; Evola, S.; Koziel, M.G. Prediction of insecticidal activity of Bacillus thuringiensis strains by polymerase chain reaction product profiles. Appl. Environ. Microbiol. 1991, 57, 3057-3061. [CrossRef]

64. Porcar, M.; Iriarte, J.; Dumanoir, V.C.; Ferrandis, M.D.; Lecadet, M.M.; Ferré, J.; Caballero, P. Identification and characterization of the new Bacillus thuringiensis serovars pirenaica (serotype H57) and iberica (serotype h59). J. Appl. Microbiol. 1999, 87, 640-648. [CrossRef] [PubMed]

65. Zghal, R.Z.; Trigui, H.; Ali, M.B.; Jaoua, S. Evidence of the importance of the Met115 for Bacillus thuringiensis subsp. israelensis Cyt1Aa protein cytolytic activity in Escherichia coli. Mol. Biotechnol. 2008, 38, 121-127. [PubMed] 
66. Guerchicoff, A.; Ugalde, R.A.; Rubinstein, C.P. Identification and characterization of a previously undescribed cyt gene in Bacillus thuringiensis subsp. israelensis. Appl. Environ. Microbiol. 1997, 63, 2716-2721. [CrossRef] [PubMed]

67. World Health Organization. Guidelines for Laboratory and Field Testing of Mosquito Larvicides; WHO: Geneva, Switzerland, 2005. article distributed under the terms and conditions of the Creative Commons Attribution (CC BY) license (http://creativecommons.org/licenses/by/4.0/). 